\title{
Blood Fibrinolytic Activity in Non-pretreated Diabetics and Its Changes Caused by Administration of Sulfonylurea (Tolbutamide)
}

\author{
Tsuneo Abe, Katsumi Endo, Uzuhiko Imagawa and Shigeyoshi Obuchi
}

The Second Department of Medicine (Prof. S. Obuchi), School of Medicine, Tokyo Medical and Dental University, Tokyo

Takeshi Abe and Mutsuyoshi Kazama

The First Department of Medicine (Prof. Y. Yoshitoshi), Faculty of Medicine, University, Tokyo, Tokyo

\section{Michio Matsuda}

The First Department of Surgery (Prof. K. Ishikawa), Faculty of Medicine, Tokyo University, Tokyo

\section{Ryosuke Ikemori}

Department of Physical Therapeutic Medicine (Prof. Y. Oshima), Faculty of Medicine, Tokyo University, Tokyo

Fibrinolytic activity of the blood was investigated on 23 diabetics comprising 19 males and 4 females. The average age of the patients was 53.2 years. None of them had received any antidiabetic treatment. They were submitted to clinical observations on a certain therapeutic schedule, which consisted particularly in tolbutamide medication for six weeks.

Depressed fibrinolytic activity, accompanied by high plasma fibrinogen contents, was found in all the 23 patients at the non-pretreatment stage but plasma proactivator, plasminogen and antiplasmin exhibited no definite tendency. At the end of one week's tolbutamide treatment, apparent elevation of blood fibrinolytic activity was observed, which was indicated by fall of blood fibrinogen content, increase in activator activity, proactivator and plasminogen level. Antiplasmin level showed no significant change. Further investigations were continued on 11 out of the 23 patients to the end of the sixth week, and it was revealed that around the third week of tolbutamide treatment fibrinolytic activity showed a tendency to return to the original low level, so to speak, a 'rebound tendency' which was observed after a transitory elevation of fibrinolytic activity in early weeks of the tolbutamide treatment. The activity fell to the original level at the end of the sixth week.

Only transient effect of antidiabetic medications to improve blood fibrinolytic activity was interpreted in association with the high incidence of vascular disorders in diabetics even under a successful control of blood sugar.

Received for publication, October 6, 1966. 
Altered fibrinolytic activity of the blood in patients with various vascular disturbances such as coronary artery disease, ${ }^{1}$ intermittent claudication, ${ }^{2}$ pulseless disease, ${ }^{3}$ thrombophlebitis, thromboangitis obliterans, etc., - has drawn much attention of investigators, and numerous interesting findings have been reported, But so far no convincing explanation has been presented about the causal relationship between fibrinolytic activity and the development of these diseases.

One of the characteristics of diabetes is the high incidence of vascular disorders. Their pathogenic association with the disease has been emphasized. The relationship between the blood fibrinolytic activity and vascular lesions in diabetics has also been a matter of interest among investigators. Although there have been reported not a few observations on this subject, they are based on the patients collected without any consideration on previous treatments which might have essential influence on the fibrinolytic activity. Furthermore, the observation is continued only for a short period.

From this point of view, only those diabetic patients were carefully selected for the present investigation, who had never received antidiabetic therapy. They were then treated with sulfonylurea (tolbutamide) for one to six weeks during the observation.

\section{Materials and Methods}

Twenty-three diabetic patients were selected who had never received any kind of antidiabetic treatment prior to their hospitalization. Out of the 23 cases 19 were males and 4 were females. Their ages ranged from 38 to 66 , the mean being 53.2. Their symptoms were rather mild in most cases, but moderate in a few. They were divided into two groups. One group consisting of 23 cases received a daily dosis of $1.5 \mathrm{~g}$ of tolbutamide for one week and was examined for the fibrinolytic activity. Another group, consisting of 11 cases, was treated with the same amount of tolbutamide every day for six weeks and their fibrinolytic activity was assessed once a week as in the former group.

The blood samples were drawn from the cubital vein at fasting and resting state early in the morning, and were mixed with $1 / 10$ volume of $2 \%$ bi-oxalate solution which had been prepared by dissolving $1.25 \mathrm{~g}$ of anmonium oxalate and $0.75 \mathrm{~g}$ of potassium oxalate in $100 \mathrm{ml}$ of distilled water.

Plasma fibriogen level ${ }^{4}$ : One $\mathrm{ml}$ of plasma was diluted to $20 \mathrm{ml}$ with saline containing $0.1 \%$ epsilon-aminocaproic acid and clotted with thrombin. This fibrin clot was washed successively with saline, distilled water, alcohol and acetone, and weighed after it was completely dried in an oven.

Plasma clot lysis time ${ }^{5}$ : Half a milliliter of plasma was put into a couple of small test tubes, mixed with $0.1 \mathrm{ml} \mathrm{M} / 10 \mathrm{CaCl}_{2}$ in an incubator to make clot, and the lysis time of this clot was measured. 
Plasma euglobulin lysis time: Euglobulin fraction of plasma, precipitated at $\mathrm{pH} 5.3$ and dissolved in the same amount of phosphate buffer, was clotted with thrombin and used for measurement of its lysis time. Blood was collected with ordinary or silicon coated glasswares, and lysis time measurement was done by the cold method of Niewiarowski. ${ }^{6}$

Fibrin plate lysis methods: Eight $\mathrm{ml}$ of $0.1 \%$ bovine fibrinogen solution were clotted with thrombin in Petri dishes and used as the standard plate, and the heated plate was prepared by heating them at $85^{\circ} \mathrm{C}$ for 30 minutes.

Lysis area produced with euglobulin fraction was measured on standard plates, and that with the mixture of $0.2 \mathrm{ml}$ of euglobulin $+0.2 \mathrm{ml}$ of 1,000 unit streptokinase (SK) and the antiplasmin level in plasma were estimated on both standard and heated plates.

\section{Results}

Blood fibrinolytic activity in non-pretreated diabetics and its shifiti induced by tolbutamide medication of one week

\section{1) Plasma fibrinogen level}

The initial plasma fibrinogen level of 23 non-pretreated patients was between 308 and $627 \mathrm{mg} / 100 \mathrm{ml}$ (the mean $447.7 \mathrm{mg} / 100 \mathrm{ml}$ ), which was much higher than that of the normal control.

After one week's tolbutamide medication, plasma fibrinogen was decreased to $242-462 \mathrm{mg} / 100 \mathrm{ml}$ in 19 cases, but increased in 4 cases, their mean value being $36.40 \mathrm{mg} / 100 \mathrm{ml}$ (Fig. 1).

\section{2) Plasma clot lysis time}

Plasma clot lysis time of 23 non-pretreated patients ranged from 3 to 10 days (the mean 6.3 days) before treatment, and tolbutamide medication shortened it to 3 to 8 days in 17 patients, but in 4 cases no changes were observed and in 2 it was prolonged, the mean after treatment being 4.9 days (Fig. 2).

\section{3) Plasma euglobulin lysis time}

a) The samples drawn with ordinary glasswares showed the initial average lysis time of 592.8 minutes in 23 non-pretreated patients. After tolbutamide medication, the average lysis time was shortened to 424.1 minutes (Fig. 3).

b) The samples drawn with silicon coated glasswares were measured for the initial average lysis time. It was 222.1 minutes in 8 out of 23 non-pretreated patients, whereas in the control it was 124.2 minutes. After tolbutamide medication, the average lysis time was shortened to 186.1 minutes (Fig. 4).

\section{4) Fibrin plate lysis}

A. Standard plate

a) Plasma euglobulin fraction developed rather small initial lysis area on 


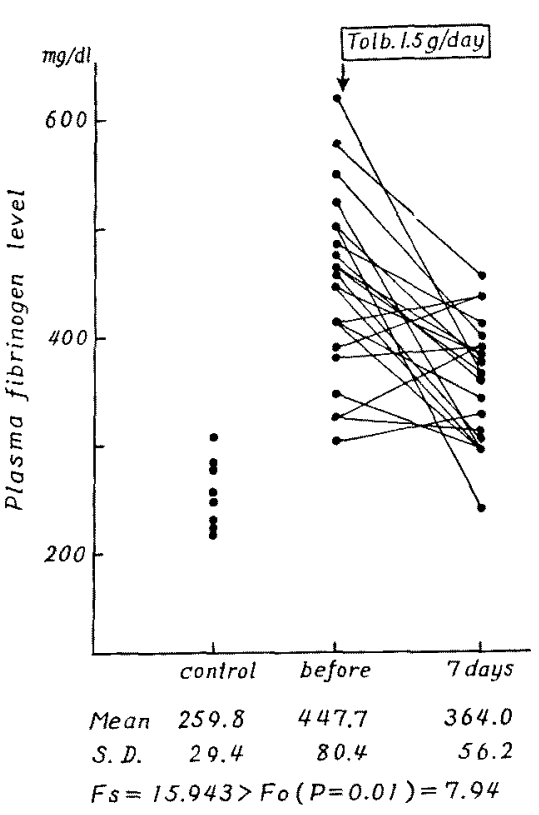

Fig. 1

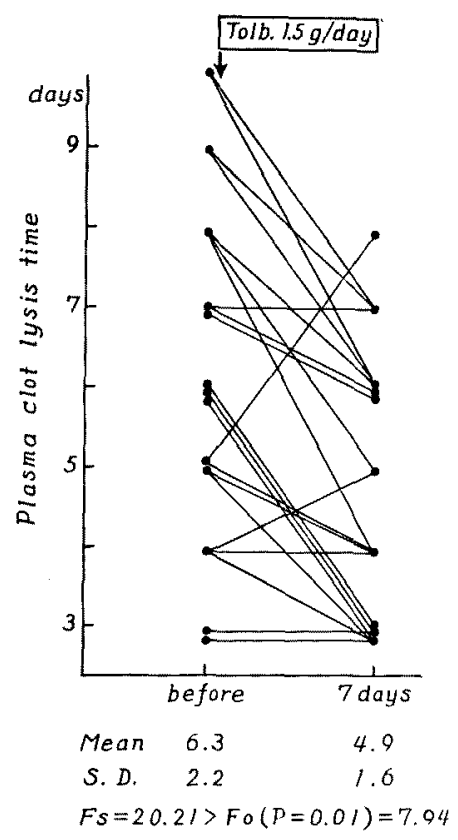

Fig. 2

Fig. 1. Reduction of plasma fibrinogen content by one week's tolbutamide medication in 23 diabetic patients.

Fig. 2. Reduction of plasma clot lysis time by one week's tolbutamide medication in 23 diabetic patients.

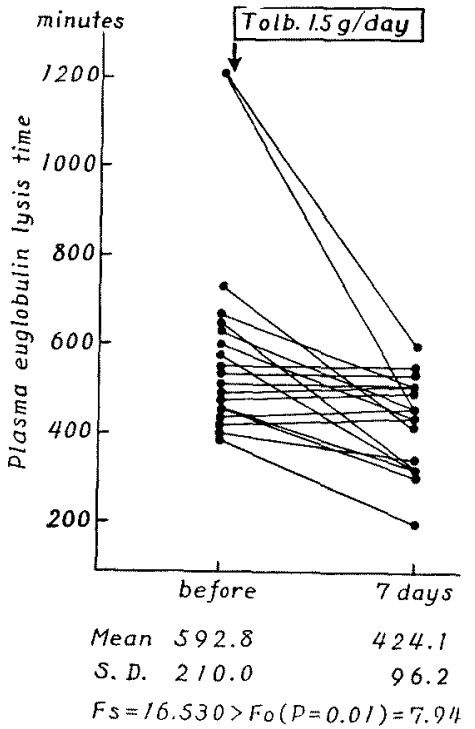

Fig. 3

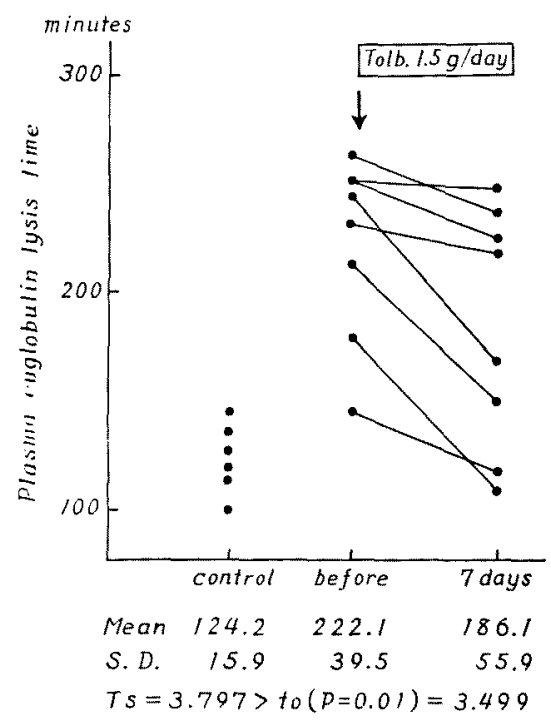

Fig. 4

Fig. 3. Reduction of plasma euglobulin lysis time by one week's tolbutamide medication in 23 diabetic patients. The blood was drawn with ordinary glasswares.

Fig. 4. Reduction of plasma euglobulin lysis time by tolbutamide medication in 8 . Y... mhn himat was drawn with silicon 


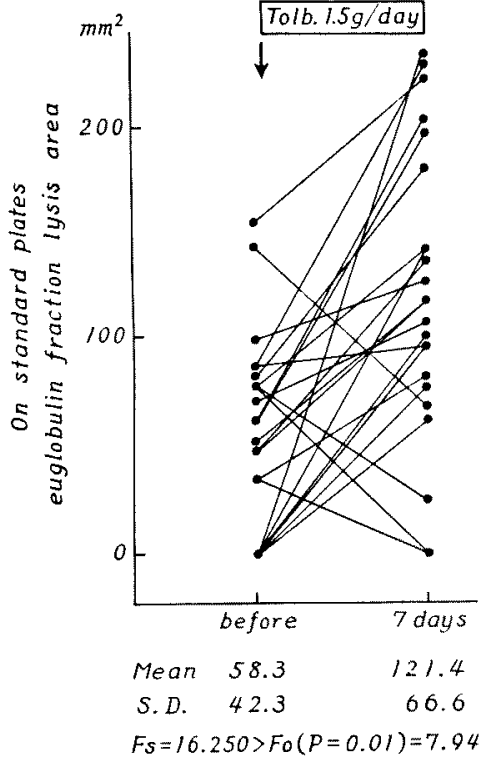

Fig. 5

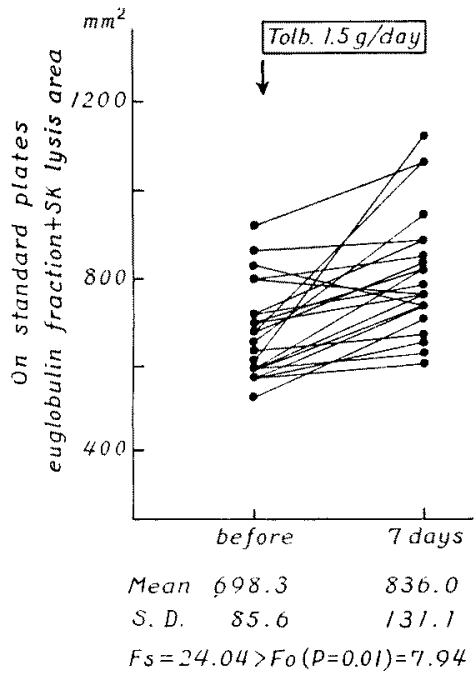

Fig. 6

Fig. 5. Increase of plasma euglobulin fraction lysis area on standard plates by one week's tolbutamide medication in 23 diabetic patients.

Fig. 6. Increase of plasma euglobulin fraction + SK lysis area on standard plates by one week's tolbutamide medication in 23 diabetic patients.

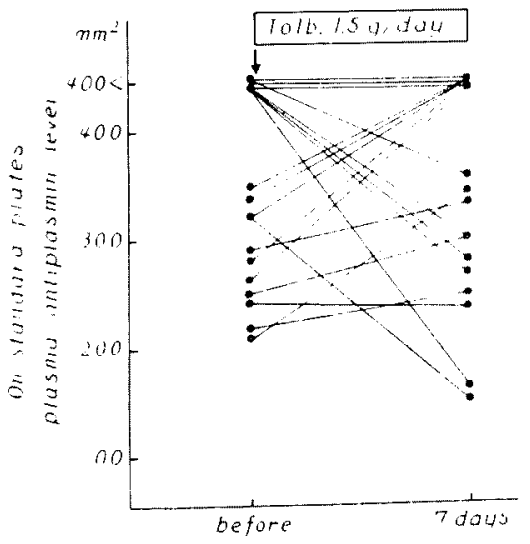

Fig. 7

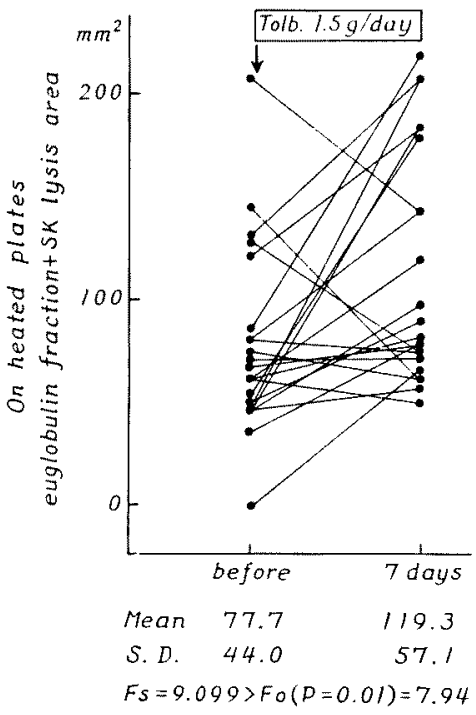

Fig. 8

Fig. 7. Variation of plasma antiplasmin level on standard plates by one week's tolbutamide medication in 23 diabetic patients.

Fig. 8. Increase of plasma euglobulin fraction + SK lysis area on heated plates by one week's tolbutamide medication in 23 diabetic patients. 


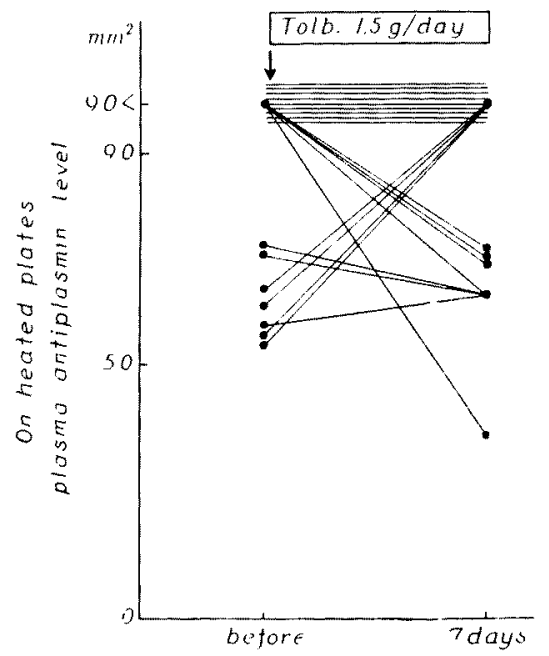

Fig. 9. Variation of plasma antiplasmin level on heated plates by one week's tolbutamide medication in 23 diabetic patients.

standard fibrin plates. Individual values scattered widely between 0 to $154 \mathrm{~mm}^{2}$ (the mean, $58.3 \mathrm{~mm}^{2}$ ) in 23 non-pretreated patients.

After tolbutamide medication it was enlarged to $121.4 \mathrm{~mm}^{2}$ on an average, but in 4 cases it was narrowed (Fig. 5).

b) The mixture of euglobulin from 23 non-pretreated patients and SK produced an initial lysis area of 552 to $928 \mathrm{~mm}^{2}$ (the mean, $698.3 \mathrm{~mm}^{2}$ ) and after tolbutamide medication, it was enlarged to 630 to $1,140 \mathrm{~mm}^{2}$ (the mean, 836.0 $\mathrm{mm}^{2}$ ), but in 2 cases it was narrowed (Fig. 6).

c) The antiplasmin level of plasma was estimated on 23 non-pretreated patients one week after commencement of tolbutamide medication. Patient's plasma was added to the control plasmin solution. No definite tendency was found in its fluctuations after treatment (Fig. 7).

\section{B. Heated plate}

a) The mixtures of plasma euglobulin fraction and SK were poured on heated plates. The results were similar to those on standard plates. The initial lysis area of plasma euglobulin fraction plus SK of the 23 non-pretreated patients averaged $77.7 \mathrm{~mm}^{2}$ and after tolbutamide treatment it increased to an average value of $119.3 \mathrm{~mm}^{2}$ (Fig. 8).

b) Plasma antiplasmin level in the 23 patients showed no significant tendency on heated plates just like on standard plates (Fig. 9). 
Changes of blood fibrinolytic activity induced by tolbutamide medication of six weeks

\section{1) Plasma fibrinogen level}

Eleven out of 23 patients were treated with tolbutamide for six weeks and examined for their plasma fibrinogen level, which ranged from 330 to $561 \mathrm{mg} /$ $100 \mathrm{ml}$. Tolbutamide medication lowered it gradually, but after the end of the third week of medication it rose or rebounded in spite of continued tolbutamide

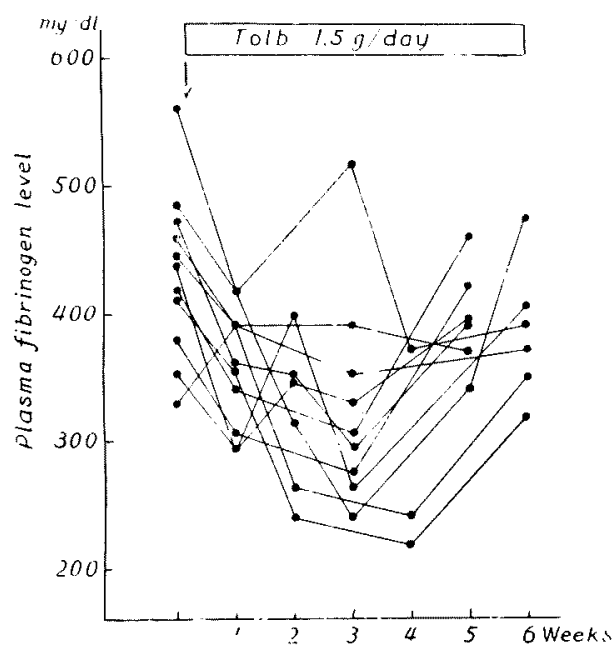

Fig. 10. Reduction of plasma fibrinogen content by six weeks' tolbutamide medication in 11 diabetic patients.

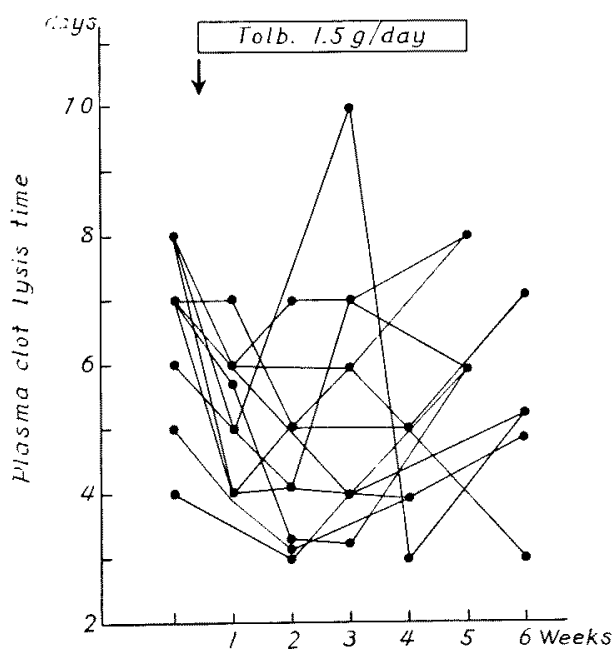

Fig. 11. Reduction of plasma clot lysis time by six weeks' tolbutamide medication in 11 diabetic patients. 


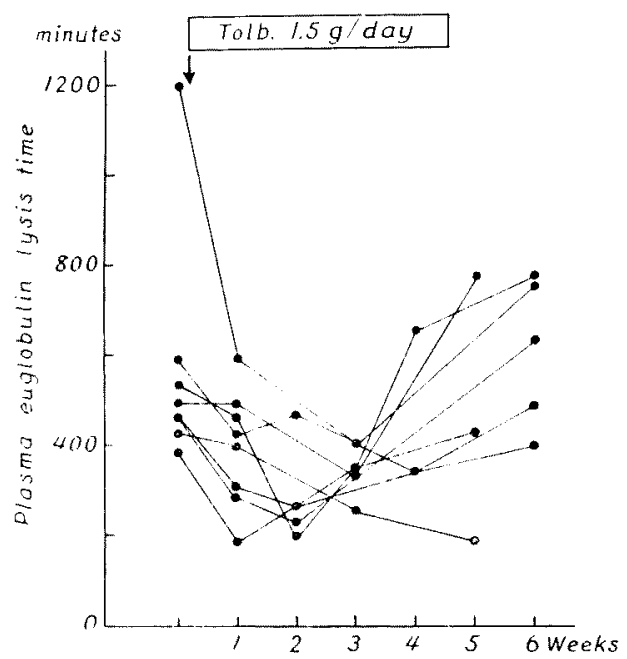

Fig. 12. Reduction of plasma euglobulin lysis time by six weeks' tolbutamide medication in 8 diabetic patients. The blood was drawn with ordinary glasswares.

medication, and at the end of the fifth or sixth week, it was restored almost to the initial level (Fig. 10).

\section{2) Plasma clot lysis time}

Plasma clot lysis time of 11 patients ranged from 4 to 8 days at the initial stage and was shortened gradually until the end of the third week of tolbutamide treatment, but thereafter it was prolonged again toward its initial value (Fig. 11).

\section{3) Plasma euglobulin lysis time}

a) Plasma samples of blood drawn with ordinary glasswares showed rather prolonged euglobulin lysis time at the initial stage in 8 patients, ranging from 400 to 1,200 minutes or more, but tolbutamide treatment induced its gradual shortening and kept it at the same level for a couple of weeks. Thereafter, however, it rebounded up and came back to its initial level at the end of the sixth week of treatment (Fig. 12).

b) Plasma samples of blood drawn with silicon coated glasswares revealed shortening of its euglobulin lysis time in 3 patients out of 11 unitl the end of the second week of tolbutamide treatment. This suggested enhanced plasminogen activator activity, but after the third week it started to rebound and at the end of the sixth week it approached to the initial value (Fig. 13).

\section{4) Fibrin plate lysis}

A. Standard plate

a) Plasma euglobulin fractions of 11 patients developed the initial lysis area ranging from 0 to $143 \mathrm{~mm}^{2}$ on standard plates, but tolbutamide medication enlarged the lysis area. After three to four weeks of treatment, however, this 


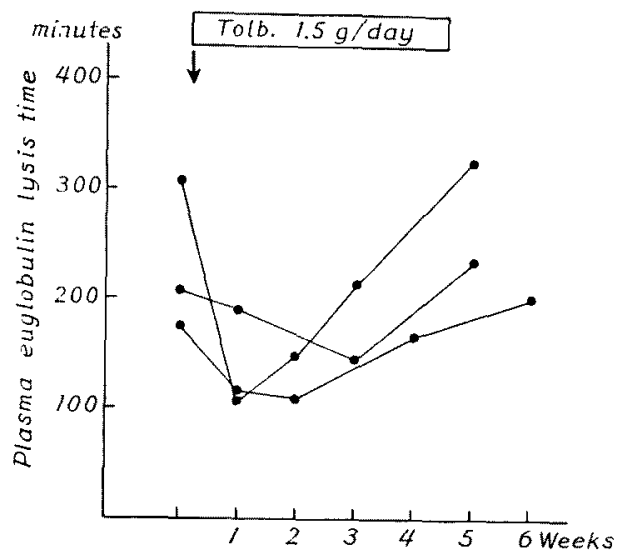

Fig. 13. Reduction of plasma euglobulin lysis time by six Tweeks' tolbutamide medication in 3 diabetic patients. The blood was drawn with silicon coated glasswares.

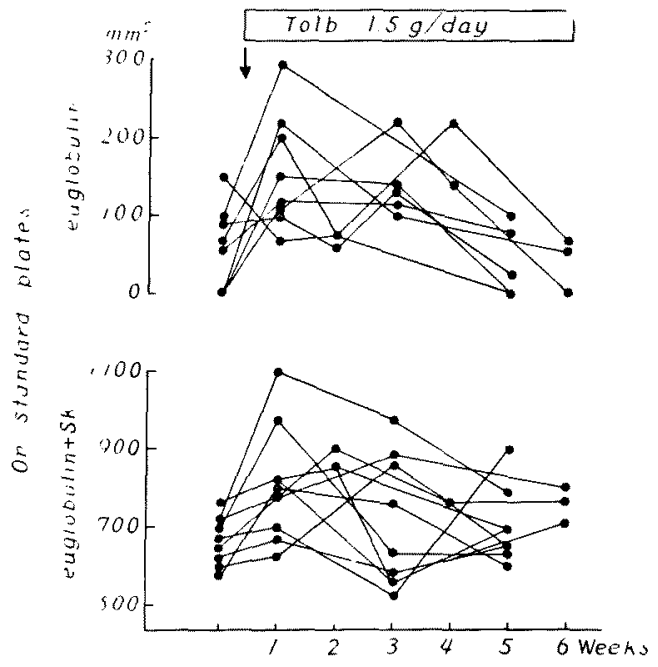

Fig. 14. Increase of plasma euglobulin fraction and euglobulin fraction $+\mathrm{SK}$ lysis area on standard plates by six weeks' tolbutamide medication in 11 diabetic patients.

began to diminish and became almost the same as the initial level at the end of the sixth week (Fig. 14).

b) The lysis area of the mixtures of plasma euglobulin fraction and SK on standard plates was also examined during six weeks of tolbutamide treatment in 10 out of 11 cases, their initial values ranging from 581 to $729 \mathrm{~mm}^{2}$. One week's medication of tolbutamide enlarged this lysis area of euglobulin fraction plus $S K$ on standard plates, the area ranging from 630 to $1,089 \mathrm{~mm}^{2}$. But at the end of the second week this showed an inclination of gradual rebound and came back to 


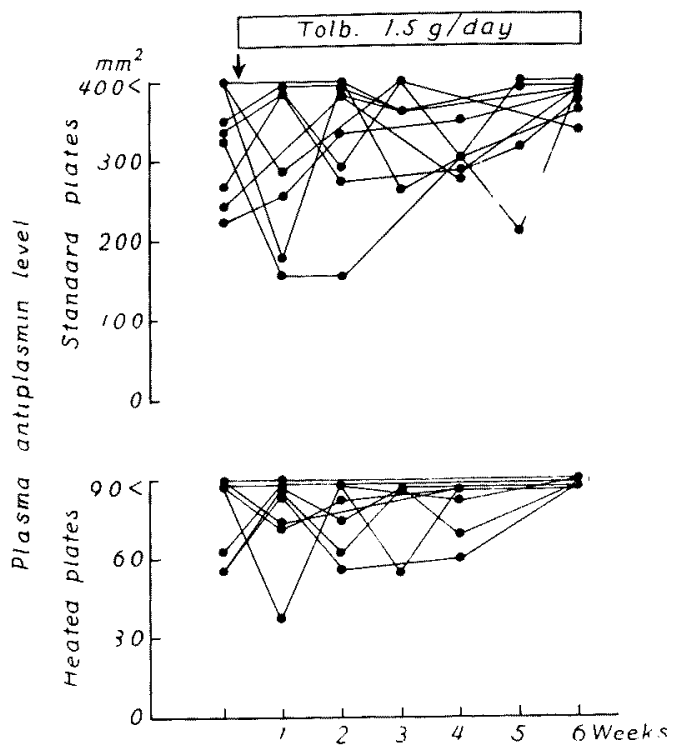

Fig. 15. Variation of plasma antiplasmin level on standard and heated plates by six weeks' tolbutamide medication in 11 diabetic patients.

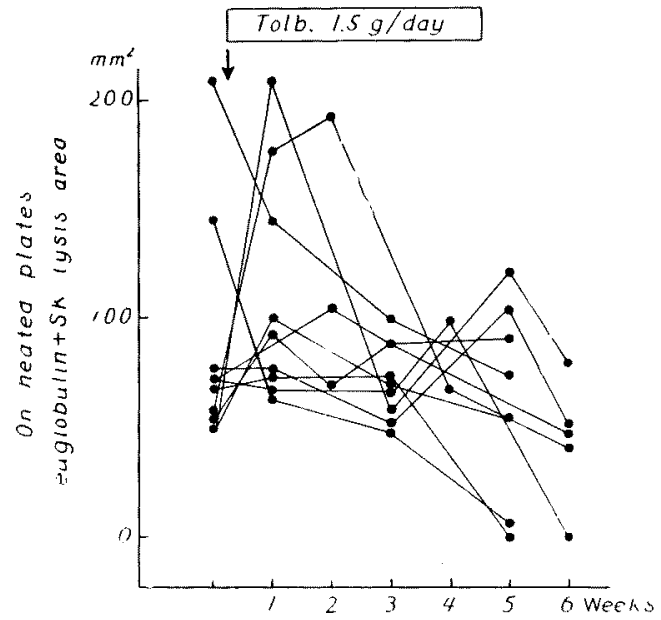

Fig. 16. Increase of plasma euglobulin fraction + SK lysis area on heated plates by six weeks' tolbutamide medication in 11 diabetic patients.

the initial value by the end of the fifth or sixth week (Fig. 14).

c) Plasma antiplasmin level was measured in 10 patients. It was revealed that its response to tolbutamide medication was variable according to individuals and had no definite tendency. But at the end of the sixth week it was invariably increased in all 10 patients to a higher level than the initial (Fig. 15). 


\section{B. Heated plate}

a) With the mixture of plasma euglobulin fraction and SK, the results on heated plates were of almost the same type as those on standard plates, the lysis area ranging from 47 to $210 \mathrm{~mm}^{2}$ in 11 patients at the initial stage. Tolbutamide medication enlarged this fibrinolytic area on heated plates during the first one or two weeks, but thereafter the area was diminished gradually and at the end of the fifth to sixth weeks it was rather smaller than the initial values (Fig. 16).

b) Plasma antiplasmin level of 11 patients was also tested on heated plates and found to have a similar tendency to that on standard plates (Fig. 15).

\section{Discussion}

The reports hitherto published on the fibrinolytic activity in diabetics are relatively limited in number. However, it has been pointed out in recent years that this activity has particular bearing on, and close relationship with, the incidence of vascular disturbances, such as myocardial infarction, ${ }^{8,9}$ intermittent claudication, ${ }^{2}$ coronary or other artery diseases, etc. ${ }^{1,10,11}$

The analytical evaluation of pathological features of diabetics and their response to insulin and/or other oral antidiabetics such as sulfonylurea (tolbutamide) have usually been made by the deviation and restoring capacity in the sugar metabolism of patients. In spite of this general tendency, the vascular disorders in diabetics cause death of the patients more frequently on account of their high incidence than the infection, which has been emphasized because of its close pathogenic relation to diabetes. It has also been proved that vascular diseases in diabetes may induce various kinds of violent and precipitous complications or severe clinical symptoms.

The treatment of diabetes mellitus consists generally in long-term schedules of insulin injection or oral medication of such antidiabetics as sulfonylurea (tolbutamide), etc. However, it is quite well known that even under well controlled sugar metabolism antidiabetic treatments have hardly a recognizable beneficial influence against the development of vascular disturbances.

Possible relationship between vascular disturbances and fibrinolytic activity in diabetics has gradually drawn attention of investigators of this field and most of the reports mention rather low levels in fibrinolytic activity in diabetics than in the healthy control. For instance, Fearnley et al. ${ }^{12}$ reported further decreased fibrinolytic activity after insulin treatment and its rebound increase with a low blood glucose level. On the other hand, however, Mackay et al. ${ }^{1 \tilde{3}}$ reported that there was no significant difference of fibrinolytic activity between diabetics and normal controls, and Hajjar and Moser ${ }^{14}$ stated that diabetics had normal plasma euglobulin lysis time. Bellet et al. ${ }^{15,17}$ applied thrombolysin to diabetics as their blood fibrinolytic activity was low, and found subsequent enhancement of 
fibrinolytic activity as well as of antiplasmin level.

We have also examined fibrinolytic activity in patients with vascular diseases, such as coronary artery disease, pulseless disease, thrombophlebitis, thromboangitis obliterans as well as in patients with diabetes mellitus, and found its lower level at least in their chronic-static stage than in healthy controls. Similar tendency was also noticed in cases of obesity. These data seem to suggest that depressed blood fibrinolytic activity is one of the pathogenic factors of vascular diseases, and consequently the low fibrinolytic activity in diabetics may have some causal relationship to their vascular disorders.

In this connection, special stress should be put on the selection of patients. The measurement of blood fibrinolytic activity must be done on the patients who have never received an antidiabetic treatment before, since the fibrinolytic activity can be influenced or modified by the treatment. Needless to say, in our investigation strict consideration was paid on this point.

As mentioned above, antidiabetic treatment has to be continued for a sufficiently long period. In our experiments six week's observation was intended in the therapeutic plan. In some cases where the patients could not stay so long in the hospital, we were obliged to curtail the period. However, we could observe a definite tendency of blood fibrinolytic activity in diabetics. The activity was rather low before treatments and was elevated even higher than the normal after the treatment.

Both insulin and sulfonylurea have been known to accelerate fibrinolytic activity in vivo, but the response of diabeties in fibrinolytic activity is different in speed according to used drugs; i.e., insulin depressed quickly this activity but only for a short period after injection, and later it caused continued elevation of fibrinolytic activity as was stated by Fearnley et al. ${ }^{12}$ The action of sulfonylurea was elicited slower, but the tendency was the same. ${ }^{16}$ So far, no report has been published regarding changes of blood fibrinolytic activity induced by longterm medication of sulfonylurea.

Our investigation was carried out in view of this point. Depressed fibrinolytic activity was observed in the stage before the medication, accompanied by increase in plasma fibrinogen content in all 23 patients. Plasma proactivator, plasminogen and antiplasmin did not show any definite tendency. At the end of one week's tolbutamide medication, apparent elevation of blood fibrinolytic activity was proved, which was indicated by fall in blood fibrinogen content, increases in activator activity, proactivator and plasminogen level. Antiplasmin level, however, showed no significant change. Further investigations were continued on 11 out of the 23 patients until the end of the sixth week, and it was revealed that under tolbutamide treatment, fibrinolytic activity showed a tendency to come back to the original depressed level around the third week, exhibiting so to speak 'rebound tendency'. After an increase in early weeks by the effect of tolbutamide, it fell down to the non-pretreatment level at the end of 
the sixth week. It was also noticed that antiplasmin level went up to the nontreatment level at that time.

It was really interesting to notice in association with the incidence of vascular disturbances which is hardly influenced by antidiabetic treatments that at the fifth to sixth weeks of tolbutamide treatment blood fibrinolytic activity came back to the non-treatment level. Although further evidence is still required to establish a definite conclusion, the results of the present investigation support the view in favor of the causal relationship between vascular disturbances and blood fibrinolytic activity.

\section{References}

1) Merskey, C., Gordon, H. \& Lackner, H. Blood coagulation and fibrinolysis in relation to coronary heart disease. Brit. med. J., 1960, 1, 219-227.

2) Nestel, P.J. Fibrinolytic activity of the blood in intermittent claudication. Lancet, 1959, 2, 373-374.

3) Atsumi, T. Decreased fibrinolytic activity and urinary excretion of steroids in Takayasu's disease and favorable effect of Anginin (Bradykinin antagonist) treatment. Jap. Circulat. J. (Jap.), 1966, 30, 85-86.

4) Permin, P.M. Undersgelser over Fibrinolytiske Enzymer. Thesis (Copenhagen), Store Nordiske Videnskabsboghandel, 1949.

5) Ratnoff, O.D. Studies on a proteolytic enzyme in human blood. Bull. Johns Hopk. Hosp., 1949, 84, 29.

6) Kowalski, E., Kopec, M. \& Niewiarowski, S. An evaluation of the euglobulin method for the determination of fibrinolysis. J. clin. Path. (Warsaw), 1959, 12, 215 218.

7) Astrup, T. \& Mullertz, S. Fibrin plate method for estimating fibrinolytic activity. Arch. Biochem., 1952, 40, 346 351 .

8) Hume, R. Fibrinolysis in myocardial infaretion. Brit. Heart J., 1958, 20, 15-20.

9) Lackner, H. \& Merskey, C. Variation in fibrinolytic activity after acute myocardial infaretion and after the administration of oral anticoagulant drugs and intravenous heparin. Brit. J. Haemat., 1960, 6, 402-413.

10) Fearnley, G.R., Chakrabarti, R. \& Avis, P.R.D. Blood fibrinolytic activity in diabetes mellitus and its bearing on ischemic heart disease and obesity. Brit. med. $J ., 1963,1,921-923$.

11) Katz, A.M., McDonald, L., Davis, B. \& Edgill, M. Fibrinolysis and blood coagulation in ischaemic heart diseases. Lancet, 1963, 1, 801-802.

12) Fearnley, G.R., Vincent, C.T. \& Chakrabarit, R. Reduction of blood fibrinolytic activity in diabetes mellitus by insulin. Lancet, 1959, 2, 1067-1069.

13) Mackay, N. \& Hume, R. Fibrinolytic activity in diabetes mellitus. Scot. med. J.. $1964,9,359$.

14) Hajjar, G.C. \& Moser, K.M. Variations in plasma fibrinogen and euglobulin activity in normal, diabetic and cirrhotic subject. Clin. Res., 1961, 9, 160.

15) Bellet. S., Sandberg, H., Tsitouris, C., Muller, O. \& Schraeder, J. Alterations in fibrinolytic parameters in the human during recovery from diabetic acidosis. Metabolism, 1961, 10, 429-438.

16) Verstraete, M., Amery, A., Maes, H. \& Vermylen, J. Influence of chlorpropamide and glucose on fibrinolytic activity. J. Lab. clin. Med. (St. Louis), 1963, 61, 926-934.

17) Bellet, S., Tsitouris, G., Schraeder, J. \& Sandberg, H. Alterations in fibrinolytic parameters in the human during recovery from diabetic acidosis. Circulation, 1960, 22, $721-722$.

18) Denborough, A. \& Betty, P. Clearing factor, fibrinolysis and blood lipids in 
diabetes mellitus. Clin. Sci., 1963, 23, 485-488.

19) Ogston, D. \& McAndrew, G. Fibrinolysis in obesity. Lancet, 1964, 5, 1205-1207. 